\title{
Treatment Approaches to Esophagogastric Junction Tumors
}

\author{
Yukinori Kurokawa ${ }^{a}$ Mitsuru Sasako $^{\text {b }}$ Yuichiro Doki ${ }^{\mathrm{a}}$ \\ ${ }^{a}$ Department of Gastroenterological Surgery, Osaka University Graduate School of Medicine, Osaka, and \\ ${ }^{b}$ Department of Upper Gastrointestinal Surgery, Hyogo College of Medicine, Nishinomiya, Japan
}

\section{Key Words}

Chemoradiotherapy · Esophagogastric junction adenocarcinoma . Postoperative adjuvant chemotherapy . Siewert classification system

\begin{abstract}
Esophagogastric junction (EGJ) adenocarcinomas are usually classified into one of the three categories of the Siewert system. The clinicopathological features of EGJ adenocarcinomas vary according to this classification scheme. The lymphatic flow in EGJ tumors of any type is mainly toward the abdomen, and nodal metastasis to the upper or middle mediastinum from Siewert type II or III tumors is relatively uncommon. Thus, the transhiatal approach is regarded as the standard in surgery for Siewert type II or III tumors, while the transthoracic approach via a right thoracotomy is recommended for Siewert type I tumors. Chemoradiotherapy followed by surgery is regarded as the standard treatment for resectable cancer of the EGJ in Western countries, but the necessity of adding radiation therapy to preoperative chemotherapy remains unknown. In the East, postoperative adjuvant chemotherapy is the current standard of care since the survival benefit was proven in pivotal randomized trials for stage II/III gastric cancer, including adenocarcinoma of the EGJ.

Copyright $\odot 2013$ S. Karger AG, Basel
\end{abstract}

\section{Introduction}

The incidence of esophagogastric junction (EGJ) tumors has rapidly increased [1]. Although EGJ tumors may comprise any histological type, the majority are adenocarcinomas. Adenocarcinomas involving the EGJ are usually classified into three categories according to the Siewert system based on their epicenter [2]. Siewert type I tumors are located $1-5 \mathrm{~cm}$ above the EGJ and usually arise from an area of intestinal metaplasia area in the esophagus, i.e. Barrett's esophagus. Siewert type II tumors, located $1 \mathrm{~cm}$ above to $2 \mathrm{~cm}$ below the EGJ, represent true carcinoma of the EGJ, arising from the epithelium of the cardia or short segments of intestinal metaplasia at the EGJ. Siewert type III tumors represent subcardial gastric cancer located $2-5 \mathrm{~cm}$ below the EGJ with invasion of the distal esophagus.

EGJ tumors portend poor survival [3, 4]. Although surgery is the most effective curative treatment, the proportion of R1 or R2 resection is comparatively high. Even with R0 resection, the recurrence rate within 2 years is also high. To improve the $\mathrm{R} 0$ resection rate and long-term outcomes, perioperative treatment has been attempted. In this review, we outline the characteristics, surgical approaches, and adjuvant treatments for EGJ tumors.

\section{KARGER}

E-Mail karger@karger.com

www.karger.com/dsu
C 2013 S. Karger AG, Basel

0253-4886/13/0302-0169\$38.00/0
Prof. Mitsuru Sasako, MD, $\mathrm{PhD}$

Department of Upper Gastrointestinal Surgery

Hyogo College of Medicine, 1-1 Mukogawa-cho

Nishinomiya, Hyogo 389-1206 (Japan)

E-Mail msasako@hyo-med.ac.jp 
Table 1. Characteristics of EGJ junction adenocarcinomas according to the Siewert classification

\begin{tabular}{llll}
\hline Siewert type & I & II & III \\
\hline Sex & male $>>$ female & male $>$ female & male $>$ female \\
Intestinal metaplasia & mostly & rare & very rare \\
Histological grade & $\mathrm{G} 1 / \mathrm{G} 2=\mathrm{G} 3 / \mathrm{G} 4$ & $\mathrm{G} 1 / \mathrm{G} 2 \leq \mathrm{G} 3 / \mathrm{G} 4$ & $\mathrm{G} 1 / \mathrm{G} 2<\mathrm{G} 3 / \mathrm{G} 4$ \\
Percentage of positive nodes & 50 & $60-70$ & 80 \\
\hline
\end{tabular}

Histological grading is based on the International Union Against Cancer (UICC) Tumor-Node-Metastasis (TNM) Classification, ed 6.

Table 2. Incidence of metastasis to regional lymph nodes of the stomach by Siewert type II tumors in three Japanese studies

\begin{tabular}{lccc}
\hline $\begin{array}{l}\text { Lymph node } \\
\text { station }^{\mathrm{a}}\end{array}$ & $\begin{array}{l}\text { National Cancer } \\
\text { Center Hospital } \\
{[12], \%}\end{array}$ & $\begin{array}{l}\text { National Cancer } \\
\text { Center Hospital }\end{array}$ & $\begin{array}{l}\text { Osaka University } \\
\text { East }^{\mathrm{b}} \text { [7], \% } \\
\text { Group [13], \% }\end{array}$ \\
\hline 1 & $38.2(86 / 225)$ & 42.1 & $61.6(53 / 86)$ \\
2 & $23.1(52 / 225)$ & 20.6 & $31.4(27 / 86)$ \\
3 & $35.1(79 / 225)$ & 23.4 & $52.3(45 / 86)$ \\
$4 \mathrm{sa}$ & $4.0(9 / 225)$ & 5.6 & $7.0(6 / 86)$ \\
$4 \mathrm{sb}$ & $1.3(3 / 225)$ & 2.8 & $3.5(3 / 86)$ \\
$4 \mathrm{~d}$ & $0.0(0 / 169)$ & 1.2 & $0.0(0 / 86)$ \\
5 & $0.6(1 / 169)$ & 3.5 & $1.2(1 / 86)$ \\
6 & $1.2(2 / 169)$ & 2.6 & $3.5(3 / 86)$ \\
7 & $20.9(47 / 225)$ & 22.4 & $25.9(22 / 85)$ \\
$8 \mathrm{a}$ & $6.2(14 / 225)$ & 6.7 & $8.5(7 / 82)$ \\
9 & $10.2(23 / 225)$ & 13.3 & $2.8(7 / 80)$ \\
10 & $4.1(6 / 147)$ & 3.9 & $20.5(15 / 73)$ \\
$11 \mathrm{p}$ & $11.1(25 / 225)$ & 14.0 & N/A \\
$11 \mathrm{~d}$ & $6.9(12 / 173)$ & 6.3 & \\
$12 \mathrm{a}$ & $0.0(0 / 102)$ & 0.0 & \\
\hline
\end{tabular}

${ }^{a}$ Based on the Japanese Classification of Gastric Carcinoma, ed 2 (English).

$\mathrm{b}$ The number of patients with positive nodes by station number is not available $(\mathrm{N} / \mathrm{A})$.

\section{Characteristics of EGJ Tumors}

The characteristics of EGJ adenocarcinomas according to the Siewert classification are shown in table 1 [5-7]. Siewert type I tumors are usually associated with intestinal metaplasia and occur more often in males. Siewert type III tumors involve intestinal metaplasia less often, and there is a higher proportion of the undifferentiated type. Siewert type II tumors fall between types I and III in most characteristics, but the proportion of human epidermal growth factor receptor 2 positivity in type II tu- mors is higher than in types I and III [8]. Although there is almost an even distribution among these three types in Western countries, there are very few Siewert type I patients in Eastern countries $[7,9,10]$. This discrepancy is probably due to differences in the prevalence of Helicobacter pylori infection and gastroesophageal reflux disorder.

The prognosis of EGJ tumors is significantly related to the extent of lymph node involvement, which is associated with lymphatic drainage from the tumor [11]. EGJ tumors, whether of the adenocarcinoma or squamous cell carcinoma type, have the potential of metastasizing to the mediastinal, perigastric, and abdominal para-aortic lymph nodes. Details on the incidence of metastasis to regional lymph nodes of the stomach by Siewert type II tumors are shown in table $2[7,12,13]$. Lymphatic flow is mainly directed toward the abdomen; most patients with pathological node-positive disease have metastases to pericardial and lesser curvature nodes (Nos. 1, 2, 3, 7) [6]. Other perigastric nodes (Nos. $4 \mathrm{sa}, 4 \mathrm{sb}, 4 \mathrm{~d}, 5,6)$ have an extremely low incidence of metastasis. Metastasis to the abdominal para-aortic area (No. 16a2) is observed in approximately $15 \%$ of EGJ patients, representing the most frequent site of nodal recurrence $[7,12]$. Considering the high proportion of metastases to the lower mediastinal lymph nodes [14], dissection of this area is necessary for treatment of EGJ tumors of any type. In contrast, nodal metastasis to the upper or middle mediastinum from Siewert type II or III tumors is relatively rare [5]; therefore, thorough dissection of this area via thoracotomy for type II and III tumors is not necessary. The most frequent type of recurrence is hematogenous spread to the liver and lung, followed by para-aortic lymph node involvement [15]. Peritoneal recurrence is rare with Siewert type I or II tumors [14] but common with type III tumors [16]. 


\section{Surgery for EGJ Tumors}

The surgical approach is mainly based on tumor location, i.e. Siewert classification. A Dutch group has conducted a randomized controlled trial comparing the right transthoracic and transhiatal approaches for Siewert type I and II tumors [17]. Perioperative morbidity was higher with the transthoracic approach. Although there were no statistically significant differences in overall survival in the entire study population between the two groups, there was a clear trend towards improved survival with the transthoracic approach. In subgroup analysis based on the Siewert classification, the advantage in 5-year overall survival with the transthoracic approach versus the transhiatal approach was as large as $14 \%$ for type I patients $(\mathrm{n}=90)$, and $-4 \%$ for type II patients $(\mathrm{n}=115)$ [18]. Due to an inadequate sample size, this study could not show any statistically significant differences, but the results strongly suggest that thorough mediastinal dissection via a right thoracotomy is necessary for Siewert type I but not for type II tumors.

A Japanese group conducted another randomized controlled trial for mainly Siewert type II and III tumors, comparing the left transthoracic and transhiatal approaches [19]. This study demonstrated that there was no survival benefit and higher morbidity associated with the transthoracic approach. The transthoracic approach also aggravated weight loss, symptoms, and respiratory functions in comparison to the transhiatal approach [20]. Subgroup analysis showed no survival benefit for Siewert type II patients with the transthoracic approach. The transhiatal approach was associated with better survival than the transthoracic approach for Siewert type III patients.

Based on these two trials, transthoracic esophagectomy with resection of the proximal stomach should be performed for EGJ type I tumors. The transthoracic approach enables lymph node dissection of the middle mediastinum, which is not accessible through the esophageal hiatus. For EGJ type II or III tumors, total gastrectomy with transhiatal resection of the distal esophagus is recommended. The thoracotomy-sparing transhiatal approach is less invasive and associated with lower morbidity and mortality. However, the transhiatal approach can lead to difficulties in obtaining sufficient margins if the tumor has invaded the distal esophagus $3 \mathrm{~cm}$ beyond the EGJ.

\section{Perioperative Treatment for EGJ Tumors}

In the late 1990s, two Western randomized controlled trials were conducted to evaluate adjuvant treatment for gastric and EGJ cancer. One was the INT 0116 trial comparing postoperative chemoradiotherapy (CRT) with 5-fluorouracil and leucovorin to surgery alone. Although CRT was associated with a large survival benefit, $90 \%$ of the patients had received insufficient lymph node dissection (D0 or D1) [21]. In addition, the MAGIC trial, which compared perioperative chemotherapy with epirubicin, cisplatin, and 5-fluorouracil to surgery alone [22], showed a significant survival benefit with perioperative chemotherapy (5-year overall survival, $36.3 \%$ in the CRT group and $23.0 \%$ in the surgery-alone group; $\mathrm{p}=0.009$ ). However, this trial also included a high proportion of patients who received insufficient D0/D1 dissections. In fact, the surgery-alone group in these trials had much shorter survival than the surgery-alone group in a Japanese randomized trial with a similar tumor stage distribution [23, 24].

In the 2000s, a Dutch CROSS randomized controlled trial evaluated preoperative CRT using carboplatin and paclitaxel for esophageal or EGJ tumors [25]. In this study, 178 patients were randomly assigned to CRT followed by surgery, and 188 to surgery alone. The preoperative CRT group had a $23 \%$ higher $\mathrm{R} 0$ resection rate than the surgery-alone group, and the pathological complete response rate in the preoperative CRT group reached $29 \%$. Overall survival was significantly better in the preoperative CRT group (5-year overall survival, $47 \%$ in the CRT group and $34 \%$ in the surgery-alone group; $\mathrm{p}=$ 0.003 ). Although the survival benefit was more prominent for the squamous cell carcinoma subset, patients with adenocarcinoma of the esophagus, including EGJ tumors, also benefited significantly from the CRT (hazard ratios for death: 0.453 in squamous cell carcinoma and 0.732 in adenocarcinoma). Based on the results of this trial, preoperative CRT became the standard for resectable esophageal and EGJ tumors in the West, although it was not a comparison between preoperative CRT and neoadjuvant chemotherapy.

In contrast, there were two large-scale randomized controlled trials with over 1,000 patients each evaluating postoperative chemotherapy for resectable gastric or EGJ tumors in East Asia. One was the Japanese ACTS-GC trial, which compared postoperative chemotherapy with S-1 for 1 year with surgery alone involving D2 dissection [26]. It showed a significant improvement in overall survival in the postoperative chemotherapy group $(\mathrm{p}=0.003)$. The recently updated results showed a $10.6 \%$ improvement in 
5 -year overall survival $(71.7 \%$ in the postoperative chemotherapy group, $61.1 \%$ in the surgery-alone group) [27]. The other study was the Korean CLASSIC trial, which compared adjuvant chemotherapy group with capecitabine plus oxaliplatin for 6 months with surgery alone involving D2 dissection. The postoperative chemotherapy group had a $15 \%$ improvement in 3-year diseasefree survival ( $74 \%$ in the postoperative chemotherapy group, 59\% in the surgery-alone group) [28]. Both trials demonstrated a significant survival benefit with postoperative chemotherapy, which led to the establishment of new standard of care for stage II or III gastric and EGJ tumors in East Asia. However, since the proportion of EGJ tumors among all patients recruited for these Asian trials was small, it is unclear whether these results can be directly applied to treatment for EGJ tumors, which is not the same as gastric cancer in tumor biology.

In Korea, the recent ARTIST randomized controlled trial evaluating the addition of radiation therapy to postoperative chemotherapy with capecitabine plus cisplatin for gastric or EGJ tumors after D2 dissection did not show a significant benefit with the addition of radiation to postoperative chemotherapy (3-year disease-free survival, 78\% in the CRT group and $74 \%$ in the chemotherapy group; $\mathrm{p}=0.09$ ) [29]. It indicated that the addition of radiation therapy to preoperative or postoperative chemotherapy as commonly performed in the West may not be effective for EGJ tumors in East Asia, where most surgeons are familiar with extensive lymph node dissection that leads to good local tumor control. Actually, the largest retrospective case series in Japan for Siewert type II tumors revealed that the local recurrence rate was very low and that the most common type of recurrence was hematogenous [12].
Most of above-mentioned trials included patients with esophageal and gastric cancers, not just EGJ tumors alone. A randomized trial involving only patients with Siewert type I-III EGJ tumors was conducted in Germany [30]. This study evaluated the addition of radiation therapy to preoperative 5-fluorouracil, cisplatin, and leucovorin, but it was prematurely closed due to low accrual. The preoperative CRT group had a relatively high pathological complete response rate of $15.6 \%$ compared to $2.0 \%$ in the preoperative chemotherapy group. Although preoperative CRT resulted in a $20 \%$ increase in 3 -year overall survival, the difference between the two groups was not statistically significant. Furthermore, postoperative mortality in the preoperative CRT group (10.2\%) was much higher than in the preoperative chemotherapy group $(3.8 \%)$. Thus, the necessity of radiation therapy in addition to chemotherapy remains unknown.

\section{Conclusions}

Siewert type II tumors can be treated with a transhiatal approach, whereas right thoracotomy and lymph node dissection of the middle mediastinum is necessary for Siewert type I tumors. Preoperative CRT is the current standard of care in the West for the treatment of cancer of the EGJ, while surgery followed by postoperative chemotherapy is currently the only evidence-based treatment available in the East. Given the less favorable outcome when compared with cancer of the distal stomach and relatively low incidence of local recurrence, clinical trials exploring the impact of neoadjuvant chemotherapy may be warranted in the future for cancer of the EGJ in the East.

\section{References}

$\checkmark 1$ Crew KD, Neugut AI: Epidemiology of upper gastrointestinal malignancies. Semin Oncol 2004;31:450-464.

$\checkmark 2$ Siewert JR, Stein HJ: Classification of adenocarcinoma of the oesophagogastric junction. Br J Surg 1998;85:1457-1459.

3 Siewert JR, Feith M, Stein HJ: Biologic and clinical variations of adenocarcinoma at the esophago-gastric junction: relevance of a topographic-anatomic subclassification. J Surg Oncol 2005;90:139-146.

4 Feith M, Stein HJ, Siewert JR: Adenocarcinoma of the esophagogastric junction: surgical therapy based on 1,602 consecutive resected patients. Surg Oncol Clin N Am 2006;15:751764.
-5 Siewert JR, Stein HJ, Feith M: Adenocarcinoma of the esophago-gastric junction. Scand J Surg 2006;95:260-269.

-6 Pedrazzani C, de Manzoni G, Marrelli D, Giacopuzzi S, Corso G, Minicozzi AM, Rampone B, Roviello F: Lymph node involvement in advanced gastroesophageal junction adenocarcinoma. J Thorac Cardiovasc Surg 2007;134: 378-385.

7 Hosokawa Y, Kinoshita T, Konishi M, Takahashi S, Gotohda N, Kato Y, Daiko H, Nishimura M, Katsumata K, Sugiyama Y, Kinoshita T: Clinicopathological features and prognostic factors of adenocarcinoma of the esophagogastric junction according to Siewert classification: experiences at a single institution in Japan. Ann Surg Oncol 2012;19:677-683.
$>8$ Schoppmann SF, Jesch B, Friedrich J, Wrba F, Schultheis A, Pluschnig U, Maresch J, Zacherl J, Hejna M, Birner P: Expression of Her-2 in carcinomas of the esophagus. Am J Surg Pathol 2010;34:1868-1873.

-9 Okabayashi T, Gotoda T, Kondo H, Inui T, Ono H, Saito D, Yoshida S, Sasako M, Shimoda T: Early carcinoma of the gastric cardia in Japan: is it different from that in the West? Cancer 2000;89:2555-2559.

10 Fang WL, Wu CW, Chen JH, Lo SS, Hsieh MC, Shen KH, Hsu WH, Li AF, Lui WY: Esophagogastric junction adenocarcinoma according to Siewert classification in Taiwan. Ann Surg Oncol 2009;16:3237-3244. 
11 Dresner SM, Lamb PJ, Bennett MK, Hayes N, Griffin SM: The pattern of metastatic lymph node dissemination from adenocarcinoma of the esophagogastric junction. Surgery 2001; 129:103-109.

-12 Yamashita H, Katai H, Morita S, Saka M, Taniguchi H, Fukagawa T: Optimal extent of lymph node dissection for Siewert type II esophagogastric junction carcinoma. Ann Surg 2011;254:274-280.

13 Fujitani K, Miyashiro I, Mikata S, Tamura S, Imamura H, Hara J, Kurokawa Y, Fujita J, Nishikawa K, Kimura Y, Takiguchi S, Mori M, Doki Y: Pattern of abdominal nodal spread and optimal abdominal lymphadenectomy for advanced Siewert type II adenocarcinoma of the cardia: results of a multicenter study. Gastric Cancer 2012, E-pub ahead of print.

- 14 Leers JM, DeMeester SR, Chan N, Ayazi S, Oezcelik A, Abate E, Banki F, Lipham JC, Hagen JA, DeMeester TR: Clinical characteristics, biologic behavior, and survival after esophagectomy are similar for adenocarcino$\mathrm{ma}$ of the gastroesophageal junction and the distal esophagus. J Thorac Cardiovasc Surg 2009;138:594-602.

15 Wayman J, Bennett MK, Raimes SA, Griffin SM: The pattern of recurrence of adenocarcinoma of the oesophago-gastric junction. $\mathrm{Br} J$ Cancer 2002;86:1223-1229.

16 Sasako M, Sano T, Tsuburaya A, Iwasaki Y, Kinoshita T, Shibata T, Fukuda H, Gastric Cancer Surgical Study Group of JCOG: Final results of a surgical, randomized, controlled trial (JCOG9502): left thoracoabdominal approach (LT) compared with abdominal and transhiatal approach (AT) for cardia or subcardia cancer (abstract 3). Gastrointestinal Cancers Symposium, Orlando, January 2010.

$\checkmark 17$ Hulscher JB, van Sandick JW, de Boer AG, Wijnhoven BP, Tijssen JG, Fockens P, Stalmeier PFM, ten Kate FJ, van Dekken H, Obertop H, Tilanus HW, van Lanschot JJ: Extended transthoracic resection compared with limited transhiatal resection for adenocarcinoma of the esophagus. N Engl J Med 2002; 347:1662-1669.

-18 Omloo JM, Lagarde SM, Hulscher JB, Reitsma JB, Fockens P, van Dekken H, ten Kate FJ, Obertop H, Tilanus HW, van Lanschot JJ: Extended transthoracic resection compared with limited transhiatal resection for adenocarcinoma of the $\mathrm{mid} / \mathrm{distal}$ esophagus: fiveyear survival of a randomized clinical trial. Ann Surg 2007;246:992-1000.
9 Sasako M, Sano T, Yamamoto S, Sairenji M, Arai K, Kinoshita T, Nashimoto A, Hiratsuka M: Left thoracoabdominal approach versus abdominal-transhiatal approach for gastric cancer of the cardia or subcardia: a randomised controlled trial. Lancet Oncol 2006; 7:644-651.

20 Kurokawa Y, Sasako M, Sano T, Shibata T, Ito S, Nashimoto A, Kurita A, Kinoshita T, Japan Clinical Oncology Group: Functional outcomes after extended surgery for gastric cancer. Br J Surg 2011;98:239-245.

21 Macdonald JS, Smalley SR, Benedetti J, Hundahl SA, Estes NC, Stemmermann GN, Haller DG, Ajani JA, Gunderson LL, Jessup JM, Martenson JA: Chemoradiotherapy after surgery compared with surgery alone for adenocarcinoma of the stomach or gastroesophageal junction. N Engl J Med 2001;345:725730.

22 Cunningham D, Allum WH, Stenning SP, Thompson JN, Van de Velde CJ, Nicolson M, Scarffe JH, Lofts FJ, Falk SJ, Iveson TJ, Smith DB, Langley RE, Verma M, Weeden S, Chua YJ, MAGIC Trial Participants: Perioperative chemotherapy versus surgery alone for resectable gastroesophageal cancer. N Engl J Med 2006;355:11-20.

23 Miyashiro I, Furukawa H, Sasako M, Yamamoto S, Nashimoto A, Nakajima T, Kinoshita T, Kobayashi O, Arai K, Gastric Cancer Surgical Study Group in the Japan Clinical Oncology Group: Randomized clinical trial of adjuvant chemotherapy with intraperitoneal and intravenous cisplatin followed by oral fluorouracil (UFT) in serosa-positive gastric cancer versus curative resection alone: final results of the Japan Clinical Oncology Group trial JCOG9206-2. Gastric Cancer 2011;14:212218.

24 Kurokawa Y, Sasako M: Recent advances in chemotherapy and chemoradiotherapy for gastrointestinal tract cancers: adjuvant chemoradiotherapy for gastric cancer. Int J Clin Oncol 2008;13:479-482.
25 van Hagen P, Hulshof MC, van Lanschot JJ, Steyerberg EW, van Berge Henegouwen MI, Wijnhoven BP, Richel DJ, Nieuwenhuijzen GA, Hospers GA, Bonenkamp JJ, Cuesta MA, Blaisse RJ, Busch OR, ten Kate FJ, Creemers GJ, Punt CJ, Plukker JT, Verheul HM, Spillenaar Bilgen EJ, van Dekken $H$, van der Sangen MJ, Rozema T, Biermann K, Beukema JC, Piet AH, van Rij CM, Reinders JG, Tilanus HW, van der Gaast A, CROSS Group: Preoperative chemoradiotherapy for esophageal or junctional cancer. N Engl J Med 2012;366:20742084.

26 Sakuramoto S, Sasako M, Yamaguchi T, Kinoshita T, Fujii M, Nashimoto A, Furukawa H, Nakajima T, Ohashi Y, Imamura H, Higashino M, Yamamura Y, Kurita A, Arai K, ACTS-GC Group: Adjuvant chemotherapy for gastric cancer with S-1, an oral fluoropyrimidine. N Engl J Med 2007;357:1810-1820.

27 Sasako M, Sakuramoto S, Katai H, Kinoshita T, Furukawa H, Yamaguchi T, Nashimoto A, Fujii M, Nakajima T, Ohashi Y: Five-year outcomes of a randomized phase III trial comparing adjuvant chemotherapy with S-1 versus surgery alone in stage II or III gastric cancer. J Clin Oncol 2011;29:4387-4393.

28 Bang YJ, Kim YW, Yang HK, Chung HC, Park YK, Lee KH, Lee KW, Kim YH, Noh SI, Cho JY, Mok YJ, Kim YH, Ji J, Yeh TS, Button P, Sirzén F, Noh SH, CLASSIC Trial Investigators: Adjuvant capecitabine and oxaliplatin for gastric cancer after D2 gastrectomy (CLASSIC): a phase 3 open-label, randomised controlled trial. Lancet 2012;379:315-321.

29 Lee J, Lim do H, Kim S, Park SH, Park JO, Park YS, Lim HY, Choi MG, Sohn TS, Noh JH, Bae JM, Ahn YC, Sohn I, Jung SH, Park CK, Kim KM, Kang WK: Phase III trial comparing capecitabine plus cisplatin versus capecitabine plus cisplatin with concurrent capecitabine radiotherapy in completely resected gastric cancer with D2 lymph node dissection: the ARTIST trial. J Clin Oncol 2012; 30:268-273.

- 30 Stahl M, Walz MK, Stuschke M, Lehmann N, Meyer HJ, Riera-Knorrenschild J, Langer P, Engenhart-Cabillic R, Bitzer M, Königsrainer A, Budach W, Wilke H: Phase III comparison of preoperative chemotherapy compared with chemoradiotherapy in patients with locally advanced adenocarcinoma of the esophagogastric junction. J Clin Oncol 2009;27: 851-856. 